\title{
RESPONSABILIDADE SOCIAL DAS ORGANIZAÇÕES EMPRESARIAIS DIANTE DO DESENVOLVIMENTO SUSTENTÁVEL
}

\section{Lucas Seolin Dias ${ }^{1}$}

\section{Maurício Dias Marques ${ }^{2}$}

RESUMO: São cada vez mais frequentes as discussões sobre questões ambientais e a utilização dos recursos naturais com equilíbrio ambiental. Este artigo faz uma reflexão sobre desenvolvimento sustentável, gestão ambiental e responsabilidade social empresarial. Foram utilizados livros e artigos para fundamentação do trabalho e demonstrou-se que as empresas devem estar atentas às questões que envolvem o meio ambiente e contribuírem com a sociedade na busca pelo uso racional dos recursos ambientais, agindo com transparência e responsabilidade, além de fortalecerem sua imagem frente à sociedade.

PALAVRAS-CHAVE: Meio Ambiente; Sustentabilidade; Desenvolvimento Sustentável; Gestão Empresarial; Gestão Ambiental; Responsabilidade Social.

\footnotetext{
${ }^{1}$ Especialista em Gestão de Marketing e Comunicação Integrada. Bacharel em Direito. Acadêmico na Universidade Estadual de Londrina - UEL. E-mail: lucas seolin@yahoo.com.br.

${ }^{2}$ Especialista em Direito Tributário e Administração Empresarial. Bacharel em Direito, Administração, Ciências Contábeis, Teologia. Licenciado em Letras. Professor da Faculdade de Ciências Contábeis de Lucélia. E-mail: mdmarques1985@gmail.com.
} 


\section{INTRODUÇÃO}

A Revolução Industrial foi um grande acontecimento na história da humanidade. Surgiram novos modelos e técnicas de produção que proporcionaram crescimentos econômicos e benefícios à humanidade. No entanto, este novo sistema industrial, acompanhado pelo fortalecimento do capitalismo, provocou perdas consideráveis no meio ambiente.

A preocupação ambiental tornou-se crescente nos últimos anos, e expressões como desenvolvimento sustentável e ecoeficiência passaram a ser discutidas, debatidas e divulgadas por governos, acadêmicos e teóricos de diversas áreas da ciência.

Um grande avanço para a sociedade veio com a tutela dos recursos naturais, sendo os impactos ambientais regulados pelo ordenamento jurídico em muitos países do mundo, inclusive no Brasil, principalmente com a Constituição de 1988.

Essas mudanças chegaram também para as empresas, que começaram a respeitar mais o meio ambiente, impulsionadas pela força da responsabilidade social, da sociedade, das leis, e da consolidação da sua imagem no mercado.

A globalização, os avanços tecnológicos, e as questões ambientais, ajudaram a formar cidadãos mais críticos e informados, e, consequentemente, consumidores conscientes.

Este trabalho tem como objetivo mostrar os principais pontos da relação sustentabilidade e gestão empresarial, e destacar a importância da responsabilidade social nesse contexto.

\section{MEIO AMBIENTE}

A redução da camada de ozônio, o aquecimento global provocado pelo efeito estufa, as mudanças climáticas, a diminuição da biodiversidade, a ameaça de destruição de ecossistemas, a contaminação dos solos, da água, dos rios e oceanos são problemas ambientais que se agravaram, principalmente no final do século $X X$, devido ao crescimento populacional das cidades, à mecanização do campo, ao aumento dos processos de fabricação industriais e à intensificação do consumo. 
Segundo Dias e Marques (2011) a degradação sofrida ao longo dos anos pode ser percebida em todas as partes do planeta, por causa das atividades da natureza, como o clima, o mar e o solo, e as ações dos seres humanos sobre ela, portanto, devemos olhar com carinho para o meio ambiente.

O Meio Ambiente é composto pela natureza física, artificial e cultural. Portanto, não é apenas a biosfera, mas também o ambiente construído. Segundo José Afonso da Silva (2000, p. 20):

O meio ambiente é, assim, a interação do conjunto de elementos naturais, artificiais e culturais que propiciem o desenvolvimento equilibrado da vida em todas as suas formas.

A Lei Federal oㅜ 6.938/81, que dispõe sobre a Política Nacional do Meio Ambiente trouxe uma definição ampla sobre o meio ambiente em seu artigo $3^{\circ}$, inciso I, que define o meio ambiente como "um conjunto de condições, leis, influências e integrações de ordem física, química e biológica, que permite, obriga e rege a vida em todas as suas formas".

Conforme disposto na lei e nos ensinamentos de Silva (2000) percebemos que o conceito de meio ambiente integra tanto a natureza original quanto a natureza artificial e cultural. O ambiente natural é o espaço físico, constituído pelo ar, água, solo, flora e as interações entre o meio e os seres vivos; o ambiente artificial é aquele composto pelas construções, as cidades, as praças, ruas, áreas verdes, etc; e o ambiente cultural compõese pelo patrimônio histórico, artístico, arqueológico, paisagístico e turístico.

A nossa Constituição Federal de 1988 trouxe preocupação com a preservação do meio ambiente, tendo inserido no seu corpo um capítulo próprio sobre a proteção do meio ambiente. Esse avanço se deve às preocupações crescentes com o Meio Ambiente principalmente após a década de 60. E ainda, nossa Carta Magna tratou de dois objetos de proteção ambiental: o meio ambiente em si, e a qualidade de vida, conforme dispõe o artigo 225 caput:

Art. 225. Todos têm direito ao meio ambiente ecologicamente equilibrado, bem de uso comum do povo e essencial à sadia qualidade de vida, impondo-se ao Poder Público e à coletividade o dever de defendê-lo e preservá-lo para as presentes e futuras gerações. 
Diante disso, podemos notar a importância dada sobre o assunto, pois o Meio Ambiente é extremamente necessário para o ser humano. Devemos preservá-lo e saber utilizar seus recursos da melhor maneira possível.

\section{DESENVOLVIMENTO SUSTENTÁVEL}

Quando falamos da melhor utilização dos recursos ambientais, deve-se entender que nos referimos à utilização que respeite o meio ambiente, ou seja, uma utilização saudável. Devemos conciliar o crescimento econômico com a preservação ambiental.

O termo desenvolvimento sustentável surgiu através dos estudos da ONU (Organização das Nações Unidas) sobre os problemas globais e as questões que acarretavam o meio ambiente, preocupações como esgotamento de recursos energéticos, mudanças climáticas e crescimento populacional.

Em uma das Conferências das Nações Unidas sobre o Meio Ambiente, na Comissão Mundial para o Meio Ambiente e o Desenvolvimento, também conhecido como Relatório de Brundtland em 1987, foi elaborada uma das definições mais difundidas sobre desenvolvimento sustentável, como sendo aquele que atende as necessidades do presente sem prejudicar as gerações futuras. Assim, o desenvolvimento sustentável

[...] é um processo de transformação no qual a exploração dos recursos, a direção dos investimentos, a orientação do desenvolvimento tecnológico e a mudança institucional se harmonizam e reforçam o potencial presente e futuro, a fim de atender às necessidades e aspirações humanas $\operatorname{CMMAD}(1991$, p.49)

O Princípio 3 da Declaração do Rio de Janeiro sobre Meio Ambiente e Desenvolvimento de 1992 determina que: "O direito ao Desenvolvimento deve ser exercido de modo a permitir que sejam atendidas equitativamente às necessidades de desenvolvimento e de meio ambiente das gerações presentes e futuras".

Existem muitas interpretações e definições sobre desenvolvimento sustentável, algumas que privilegiam mais o aspecto econômico, outras o aspecto social, sendo que todas possuem em seu seio características comuns que evidenciam as bases do desenvolvimento sustentável.

$\mathrm{Na}$ "Cúpula da Terra" (Conferência das Nações Unidas sobre o Meio Ambiente e o Desenvolvimento) no Rio de Janeiro, 1992, foi elaborado um documento que ficou 
conhecido como a Agenda 21, no qual foram destacados os principais pontos para se chegar ao desenvolvimento sustentável.

Conforme Laville (2009, p.25) 'A Agenda 21 é um plano de ação global que determina três pilares fundadores do desenvolvimento sustentável: a igualdade social, 0 meio ambiente e a economia"

Importante pensarmos que estes três pilares devem ser trabalhados de forma integrada, para não haver uma sobreposição de alguma área, enfraquecendo uma ou outra coluna, dificultando o equilíbrio.

\title{
3.1 Desenvolvimento Sustentável e as Organizações
}

Podemos notar que na atualidade, sustentabilidade tem sido analisada sobre diversos prismas, entre eles: a preocupação com o meio ambiente natural e artificial; legislações ambientais; novas oportunidades de mercado e do ponto de vista do consumidor consciente.

A ética aliada à responsabilidade social e ambiental impulsiona o desenvolvimento sustentável, e as instituições estão percebendo que a adoção de medidas sustentáveis, além de ser essencial para elas, é importante para toda a sociedade.

Segundo Vinha, 2010, p. 196:

\begin{abstract}
A recente associação do princípio de responsabilidade social empresarial aos preceitos do Desenvolvimento Sustentável ampliou a compreensão do conceito de ecoeficiência ao estender a ação preventiva de impactos ao conjunto da cadeia produtiva. A partir de então, pelo menos no plano da retórica, um grande contingente de empresas em todo o mundo abraçou a causa da responsabilidade social.
\end{abstract}

Em 1998, no Brasil, a Confederação Nacional da Indústria (CNI) define e publica sua Declaração de Princípios da Indústria para o Desenvolvimento Sustentável, o que mostra maior preocupação das empresas sobre as questões que envolvem a sustentabilidade. Neste sentido, as organizações vêm assumindo formas de gestão mais eficientes, respeitando o meio ambiente, a economia e o aspecto social.

Podemos encontrar três dimensões da sustentabilidade empresarial como também nos ensina Reinaldo Dias (2006): a econômica, a social e a ambiental. 
A econômica prevê que as empresas têm que ser economicamente viáveis, levando em conta o aspecto da rentabilidade. Em termos sociais, a empresa deve satisfazer aos requisitos de proporcionar as melhores condições de trabalho aos seus empregados, procurando contemplar a diversidade cultural existente na sociedade em que atua. Do ponto de vista ambiental, deve a organização pautar-se pela ecoeficiência dos seus processos produtivos, preocupar-se com a produção mais limpa, oferecer condições para o desenvolvimento de uma cultura ambiental organizacional, e adotar uma postura de responsabilidade ambiental.

O referido autor acrescenta que o mais importante é o equilíbrio entre as três dimensões, podendo atuar como representantes dessas esferas as organizações empresarias, sindicatos, e entidades ambientais.

Isto posto, percebemos que cada vez mais as instituições estão atentas às questões sobre sustentabilidade. Durante muito tempo achava-se que os recursos naturais fossem infinitos, no entanto, estudiosos demonstraram que deveríamos prestar mais atenção no meio ambiente e zelar por ele, o que fez com que surgisse o conceito de desenvolvimento sustentável tal como vemos hoje, do qual muito se fala a respeito, e que tem como principal aspecto desenvolver-se economicamente e socialmente desde que se atenda às gerações atuais e futuras.

\section{EMPRESAS, MEIO AMBIENTE E RESPONSABILIDADE SOCIAL}

As empresas são responsáveis pela grande parte de alterações feitas no meio ambiente, pois elas utilizam os recursos naturais para obtenção de bens, prejudicando grandemente a natureza. Muitas empresas contaminaram o meio ambiente natural desde a Revolução Industrial no século XIX, ocasionando inúmeros estragos ao redor do planeta.

Segundo Dias (2006, p.46) "quando se explora o meio ambiente, que é um bem comum, buscando o benefício privado, podem ser causados impactos ambientais que afetam negativamente o bem-estar de outras pessoas que não tem relação com quem os gera".

Se uma empresa trabalha bem seus recursos, preocupa-se com o meio ambiente em geral, seu nível de competitividade aumenta. Uma organização bem estruturada e bem administrada, que organiza seus processos de produção de forma que respeite as 
questões ambientais, que gerencie seus recursos tecnológicos, humanos e financeiros de forma ecoeficiente, estará elevando sua reputação e aceitação frente aos diversos públicos.

Neste sentido, a responsabilidade social apresentou-se como um grande aliado para a sociedade e as organizações. Conforme Vinha, 2010, p.196:

\begin{abstract}
[...] a responsabilidade social empresarial (ou corporativa) teve o mérito de regatar valores morais que a sociedade, em geral, não associava às empresas. Além de considerar um compromisso permanente dos empresários com a integridade do meio ambiente e com os direitos humanos, pressupõe uma postura ética nos negócios e a transparência na comunicação com a sociedade.
\end{abstract}

Para Kotler \& Armstrong (2007, p. 532) "uma empresa socialmente engajada toma decisões de marketing de acordo com os desejos e os interesses dos consumidores, os requisitos da empresa e interesses de longo prazo da sociedade"

Portanto, as empresas deveriam investir em uma gestão socioambiental eficiente, pois os ganhos em longo prazo são enormes. Há diversas razões que podem incentivar uma empresa a adotar métodos de gestão sócio ambiental, além dos interesses econômicos, como preceitua Reinaldo Dias (2006 p. 56), dividindo em: Estímulos internos, como a necessidade de redução de custos; incremento na qualidade do produto; melhoria da imagem do produto e da empresa; a necessidade de inovação; aumento da responsabilidade social; sensibilização do pessoal interno. E, estímulos externos, como a demanda do mercado; a concorrência, o poder público e a legislação ambiental; o meio sociocultural; e as certificações ambientais.

Como podemos perceber, são muitas as questões que vêm corroborar para estimular uma empresa utilizar técnicas de gestão ambiental. Dentre elas destacamos a melhoria da imagem do produto e da empresa, que diz respeito à reputação da empresa junto aos seus públicos, desde os consumidores até aos fornecedores e colaboradores; o meio sociocultural, que são as pressões exercidas principalmente por consumidores e a sociedade, trazendo à mídia questões ambientais que podem desvalorizar a empresa; e a responsabilidade social, pois a empresa faz parte da sociedade e deve agir de forma responsável, tendo deveres e obrigações. Deve agir ética e moralmente de forma aceitável, portanto deve respeitar o meio ambiente. 


\section{CONSIDERAÇÕES FINAIS}

No decorrer deste trabalho podemos notar os grandes desafios que cercam 0 desenvolvimento sustentável, sobretudo, no que envolve as empresas que foram afetadas amplamente pela política do lucro, a qualquer custo, incentivadas pelo modelo capitalista implantado ao longo dos anos.

Passeamos pela conceituação de Meio Ambiente, fizemos reflexões acerca da sustentabilidade, e abordamos questões sobre a gestão e responsabilidade social nas organizações. Relatou-se que o desenvolvimento sustentável deve ser trabalhado sobre 3 colunas centrais, quais sejam, a econômica, a social e a ambiental.

Por fim, vimos a importância da sustentabilidade nas empresas e da gestão ambiental alicerçada nos ditames da responsabilidade social. Fica claro que as empresas devem ser ambientalmente corretas, transparentes e responsáveis, para que se consolidem e se fortaleçam perante seus mais variados públicos, além de contribuírem para um meio ambiente mais equilibrado e saudável.

É responsabilidade das empresas, principalmente as indústrias que utilizam matéria-prima extraída da natureza, conciliar seu crescimento econômico com a preservação do meio ambiente, pois só assim essas empresas serão socialmente bem aceitas e trabalharão com ecoeficiência.

\section{REFERÊNCIAS BIBLIOGRÁFICAS}

BRASIL. Constituição (1988). Constituição da República Federativa do Brasil. Brasília, DF, senado. 1988.

. Lei Federal no 6.938, de 31.08.1981. Política Nacional do Meio Ambiente.

CMMAD - Comissão Mundial sobre Meio Ambiente e Desenvolvimento. Nosso futuro

comum. 2a ed. Rio de Janeiro: FGV, 1991. 
DIAS, Lucas Seolin; MARQUES, Maurício Dias. Meio Ambiente e a Importância dos

Princípios Ambientais. Disponível em: <http://www.amigosdanatureza.org.br/publicacoes/ index.php/forum ambiental/article/view/152> Acesso em: 15/09/2013.

DIAS, Reinaldo. Gestão ambiental: responsabilidade social e sustentabilidade. São Paulo: Atlas, 2006.

Marketing ambiental: ética, responsabilidade social e competitividade nos negócios. - 1.ed.- 3. reimpr. - São Paulo: Atlas, 2009.

KOLTER Philip \& ARMSTRONG Gary: Princípios de Marketing. 12. ed. São Paulo: Pearson Prentice Hall, 2007.

LAVILLE, Élisabeth. A empresa verde. [Tradução Denise Macedo] São Paulo: ÓTE, 2009.

SILVA, José Afonso da. Direito ambiental constitucional. $3^{a}$ ed. São Paulo: Malheiros Editores. 2000.

URSINI, Tarcila Reis; BRUNO, Giuliana Ortega. A Gestão para a Responsabilidade Social e - Desenvolvimento Sustentável. Disponível em $<$ http://www.ethos.org.br/ Uniethos/Documents/RevistaFAT03 ethos.pdf>. Acesso em: 05/04/2013.

VINHA, Valéria da. As empresas e o desenvolvimento sustentável: a trajetória da construção de uma convenção. In: MAY, P. H. (org). Economia do meio ambiente: teoria e prática. Rio de Janeiro: Elsevier, 2010. p.181-204. 